\title{
ISOLAMENTO DE Arcanobacterium pyogenes DE GRANULOMA ACTINOMICÓIDE EM BOVINO
}

\author{
ISOLATION OF Arcanobacterium pyogenes OF ACTINOMYCOTIC-LIKE \\ GRANULOMA IN A COW
}

\author{
Bruna da Rosa Curcio $^{1}$ Fabiane Resende Gomes ${ }^{2}$ Dário Milanez Melo ${ }^{3}$ \\ Margarida Buss Raffi ${ }^{4}$ Franklin Riet-Correa ${ }^{5}$ Sílvia Regina Leal Ladeira ${ }^{6}$
}

\section{- RELATO DE CASO -}

RESUMO

Foi observada em um bovino com suspeita de lechiguana, uma lesão arredondada de consistência dura na região sub-mandibular que media $12 \times 11 \times 7 \mathrm{~cm}$. Foram realizadas biópsias cirúrgicas para estudos bacteriológico e histológico, teste de tuberculinização intra-dérmico e coleta de sangue, a fim de realizar o teste de imunodifusão radial para o diagnóstico de lechiguana. Posteriormente, foi realizada eutanásia e necropsia do animal. No resultado das biópsias, não se obteve isolamento bacteriano e o estudo histológico não foi conclusivo. Os testes de tuberculinização e de imunodifusão apresentaram resultado negativo. Na necropsia, constatou-se que a lesão consistia de um nódulo, formado por uma cápsula de tecido conjuntivo envolvendo uma massa esbranquiçada com grânulos amarelados de até $3 \mathrm{~mm}$ de diâmetro. Através de histologia, constataram-se piogranulomas multifocais, com um infiltrado de neutrófilos circundando rosetas formadas por colonias bacterianas no centro e corpúsculos de Splendore-Hoeppli na periferia; ao redor desse infiltrado purulento observaram-se células epitelióides e tecido fibroso infiltrado por linfócitos. Arcanobacterium pyogenes foi isolado em cultura pura do material obtido na necropsia. Conclui-se que A. pyogenes poderia ter participação na etiologia de granuloma com características clínicas e patológicas semelhantes à lechiguana, tuberculose e actinobacilose.

Palavras-chave: granuloma actinomicóide, granuloma, Arcanobacterium pyogenes, bovinos.
SUMMARY

A round hard lesion measuring $12 \times 11 \times 7 \mathrm{~cm}$, with a presumptive diagnosis of lechiguana, was observed in the submandibular region of a cow. Bacteriologic and histologic examinations from biopsies from the lesion were not conclusive. The intradermic test for tuberculosis was negative. The immunodiffusion serologic test to detect antibodies against Pasteurella granulomatis was negative. The animal was killed and necropsied. The submandibular lesion consisted in a hard whitish tissue with yellowish granules measuring up to $3 \mathrm{~mm}$ scattered within it. A fibrous capsule was surrounding the lesion. Histologically, the lesion was characterized by multifocal piogranulomas with rosetes made up of bacterial colonies in their center, surrounded by Splendore-Hoeppli reaction and neutrophils at the periphery. Epithelioids cells, and fibrous tissue infiltrated by lymphocytes were observed around those lesions. Arcanobacterium pyogenes in pure culture was isolated from samples obtained at necropsy. It is concluded that A. pyogenes could be involved in actinomycotic-like lesion with clinical and pathological aspects similar to lechiguana, tuberculosis and actinobacilosis.

Key words: actinomycotic-like granuloma, granuloma, Arcanobacterium, cattle.

\footnotetext{
${ }^{1}$ Acadêmica em Medicina Veterinária, Faculdade de Veterinária, Universidade Federal de Pelotas (UFPel), Laboratório Regional de Diagnóstico, CP 354, 96010-900, Pelotas - RS. E-mail: curciobr@tutopia.com.br. Autor para correspondência.

${ }^{2}$ Médico Veterinário, MSc. Professora Substituta de Imunologia, UFPel.

${ }^{3}$ Médico Veterinário Autônomo.

${ }^{4}$ Médico Veterinário, MSc., Professor Assistente de Patologia Animal, UFPel.

${ }^{5}$ Médico Veterinário, DSc. Professor Titular de Patologia Animal, UFPel.

${ }^{6}$ Médico Veterinário, MSc., Técnica do Laboratório Regional de Diagnóstico, Faculdade de Veterinária, UFPel. E-mail: sladeira@pro.via-rs.com.br.
} 


\section{INTRODUÇ̃̃̃O}

$\begin{array}{cccc}\text { As } & \text { doenças classificadas } & \text { como } \\ \text { granulomas } & \text { actinomicóides } & \text { são } & \text { lesões }\end{array}$ piogranulomatosas com presença de rosetas semelhantes às observadas na actinomicose e actinobacilose (WEISS \& SANTOS, 1992; PALMER, 1992). Além de Actinomyces bovis e Actinobacillus ligneriesii, outras bactérias incluindo Nocardia spp., Staphylococcus aureus, Streptococcus spp., Pseudomonas aeruginosa e Arcanobacterium pyogenes podem causar esses granulomas (SHANAV \& DAVIS, 1942; PALMER, 1992). Rosetas com presença de corpúsculos de Splendori-Hoeppli podem ser observadas, também, na lechiguana (RIET-CORREA et al., 2000). Os granulomas actinomicóides são encontrados freqüentemente em matadouros frigoríficos no Rio Grande do Sul, onde estudos durante um período de sete anos, detectaram lesões sugestivas de actinobacilose em $1,15 \%$ dos bovinos abatidos (MONDADORI et al., 1994) e lesões granulomatosas semelhantes à tuberculose em $0,64 \%$ dos animais (ANDRADE et al., 1991). As lesões semelhantes à actinobacilose são preferencialmente observadas em linfonodos, língua e lábios dos bovinos abatidos (MÉNDEZ, 1998).

A. pyogenes tem como habitat natural as superfícies mucosas, principalmente da cavidade oral e nasofaringe. As infecções por este microrganismo são geralmente endógenas e na maioria das espécies provocam abscessos nos tecidos. Em bovinos, ovinos e suínos pode causar mastite crônica ou aguda, pneumonia supurativa, artrite séptica, endocardite vegetativa, endometrite, sinusite crônica, infecções umbilicais, vesiculite seminal e infecções secundárias em ferimentos (QUINN et al., 1994; GYLES, 1986; WARD \& REBHUN, 1992). Em bovinos, A. pyogenes está freqüentemente relacionado como etiologia de abscessos hepáticos, aparentemente, agindo em sinergismo com Fusobacterium necrophorum (NARAYANAN et al., 1998a).

Na região de abrangência do Laboratório Regional de Diagnóstico (LRD/FV/UFPel), é comum o aparecimento de casos de lechiguana, que geralmente são enviados por produtores locais com o objetivo de diagnóstico e indicação de tratamento para a enfermidade. A lechiguana é uma doença dos bovinos definida como uma paniculite focal, fibrogranulomatosa, proliferativa, caracterizada por uma tumoração de crescimento rápido e que tem como etiologia a Mannheimia granulomatis (Pasteurella granulomatis). Clinicamente, observase um aumento de volume localizado com mobilidade subcutânea (RIET-CORREA et al., 2000), podendo, desta forma, ser confundida com granulomas de etiologias diferentes.

O objetivo do presente estudo foi determinar a etiologia de um granuloma subcutâneo em bovino enviado ao LRD com diagnóstico presuntivo de lechiguana.

\section{RELATO DO CASO}

Foi recebida no LRD uma fêmea bovina mestiça em avançado grau de emagrecimento, com suspeita de lechiguana. Apresentava um nódulo de consistência endurecida $(12 \times 11 \times 7 \mathrm{~cm})$, na região do linfonodo mandibular, com alopecia, edema local e presença de fístulas com descarga serosanguinolenta. (Figura 1).

O material para diagnóstico foi coletado através de biópsia cirúrgica, sendo submetido a estudo bacteriológico e histológico. Para o estudo histológico, o material foi fixado em formol $10 \%$, incluído em parafina, cortado em secções de $5 \mu \mathrm{m}$ de espessura e corado pela técnica de hematoxilinaeosina (LUNA, 1968). O material submetido ao exame bacteriológico foi semeado em ágar sangue ovino $5 \%$ e incubado em estufa a $37^{\circ} \mathrm{C}$ em aerobiose durante 48 horas. Após o crescimento de colônias puras, a caracterização foi feita através do estudo do tempo de crescimento e características da colônia, características morfotintoriais da bactéria pela técnica de Gram e provas bioquímicas segundo BARROW \& FELTHAM (1993).

O animal foi submetido, também, ao teste de tuberculinização intradérmica caudal e foi colhido sangue para realizar o teste de imunodifusão radial frente à $\boldsymbol{M}$. granulomatis. $\mathrm{O}$ teste de

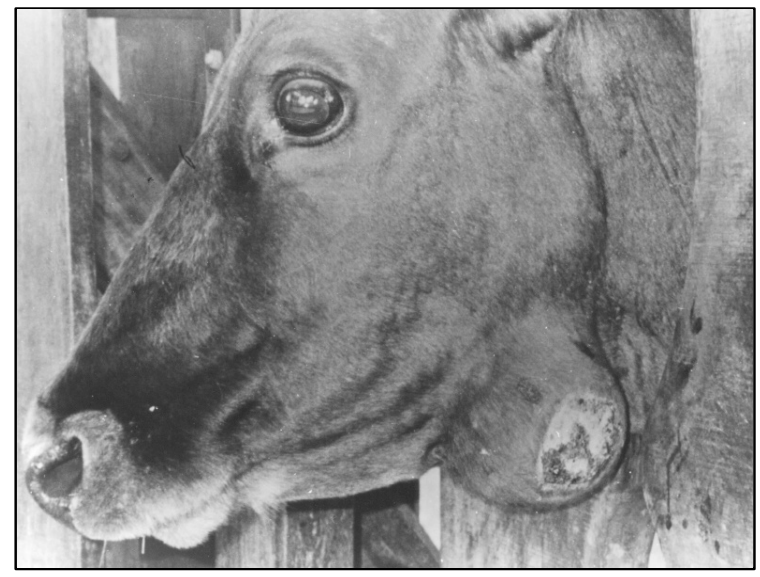

Figura 1 - Tumoração localizada na região submandibular, medindo $12 \times 11 \times 7 \mathrm{~cm}$. Observam-se fístulas com descarga de conteúdo sero-sanguinolento e área de alopecia. 
imunodifusão foi baseado na técnica de OUCHTERLONY (1948) modificada por PUGH et al. (1971). Posteriormente, o animal foi sacrificado e realizou-se a necropsia para obtenção de material para estudo histológico e bacteriológico utilizandose as técnicas mencionadas anteriormente.

\section{RESULTADOS E DISCUSSÃO}

Não houve crescimento bacteriano a partir do material obtido das biópsias e, no estudo histológico, observou-se apenas a presença de tecido conjuntivo, o que não foi conclusivo para a definição do diagnóstico. O teste de imunodifusão radial frente à M. granulomatis não apresentou formação de bandas de precipitação. Com base nestes resultados, foi possível concluir que o caso não se tratava de lechiguana, já que o diagnóstico desta enfermidade é realizado pelo isolamento do agente a partir do material da biópsia e identificação histológica de linfangite eosinofílica, microabscessos contendo rosetas de Splendore-Hoeppli e abundância de fibras colágenas (RIET-CORREA et al., 2000).

$\mathrm{O}$ estado de caquexia em que se encontrava o bovino devia-se, provavelmente, à localização da tumoração que levava à dificuldade de preensão e mastigação, à disfagia e, com isso, emagrecimento progressivo, já que não foram encontradas lesões em outros órgãos. Mesmo com tratamento de suporte, que consistiu na administração de fluidoterapia (Glicose $5 \%$ e Ringer Lactato), vitaminas do complexo B e antibioticoterapia (Penicilina), o animal continuava em progressivo estado de caquexia, sendo então, sacrificado. Na necropsia, observou-se um nódulo, situado no linfonodo mandibular, formado por cápsula de tecido conjuntivo envolvendo massa esbranquiçada com conteúdo purulento contendo grânulos que mediam entre 1 e $3 \mathrm{~mm}$ de diâmetro. Durante a necropsia, não foram encontradas lesões em outros órgãos. $\mathrm{Na}$ histologia, constataram-se piogranulomas multifocais, com infiltrado de neutrófilos circundando rosetas formadas por colônias bacterianas no centro e corpúsculos de Splendore-Hoeppli na periferia; ao redor desse infiltrado purulento, observaram-se células epitelióides e, mais na periferia, tecido fibroso infiltrado também por linfócitos (Figura 2). Entre os piogranulomas, havia uma marcada fibroplasia do tecido linfático.

No exame bacteriológico, após 48 horas de incubação, observou-se o crescimento de colônias pequenas e translúcidas com uma área de hemólise completa ao seu redor. No esfregaço, corado pela técnica de Gram, constatou-se a presença de cocobacilos Gram positivos. Com a realização de testes bioquímicos (Tabela 1), o agente foi caracterizado como Arcanobacterium pyogenes, o qual foi isolado em cultura pura do material obtido na necropsia. A bactéria isolada foi enviada para Maryland Regional College of Veterinary Medicine - Vírgínia, onde também foi identificada como $\boldsymbol{A}$. pyogenes pelo Dr. Gordon R. Carter.

A. pyogenes pertence à família Actinomycetaceae, que são microrganismos Gram positivos que tendem a crescer como filamentos. Devido a esta característica, alguns actinomicetos causam abscessos granulomatosos crônicos no tecido subcutâneo (GYLES, 1986). Para a caracterização desse agente, são características importantes as reações de catalase e hidrólise da esculina negativas e a hidrólise da gelatina positiva. Em geral, as cepas de $\boldsymbol{A}$. pyogenes possuem grande atividade leucotóxica e hemolítica (NARAYANAN et al., 1998b). A presença de nódulos endurecidos com cápsula fibrosa que envolve uma cavidade contendo pus amarelado e grânulos é característica dos granulomas actinomicóides (WEISS \& SANTOS, 1992; McGAVIN, 1998).

A actinobacilose e os piogranulomas estafilocócicos são as causas mais comuns desses granulomas, entretanto outras bactérias como Nocardia spp., Staphylococcus aureus, Streptococcus spp., Pseudomonas aeruginosa e Arcanobacterium pyogenes podem causar granulomas actinomicóides (SHANAN \& DAVIS, 1942; PALMER, 1992). Estas enfermidades devem ser diferenciadas através da histoquímica e/ou cultura dos microrganismos (WEISS \& SANTOS, 1992).

Pelas características clínicas e a aparência da lesão macroscópica, o presente caso poderia ser facilmente confundido com actinobacilose, já que esta ocorre geralmente de forma esporádica e crônica, causando piogranulomas nos tecidos moles. A forma de actinobacilose que acomete os linfonodos é a mais freqüentemente observada no Rio Grande do Sul, onde são afetados, principalmente os linfonodos retrofaríngeos, parotídeos e submandibulares. A confirmação do diagnóstico é realizada pelo isolamento de Actinobacillus lignieresii do pus ou pela observação de lesões características no estudo histológico (MÉNDEZ, 1998). A lesão observada poderia ser confundida, também, com actinomicose, no entanto 


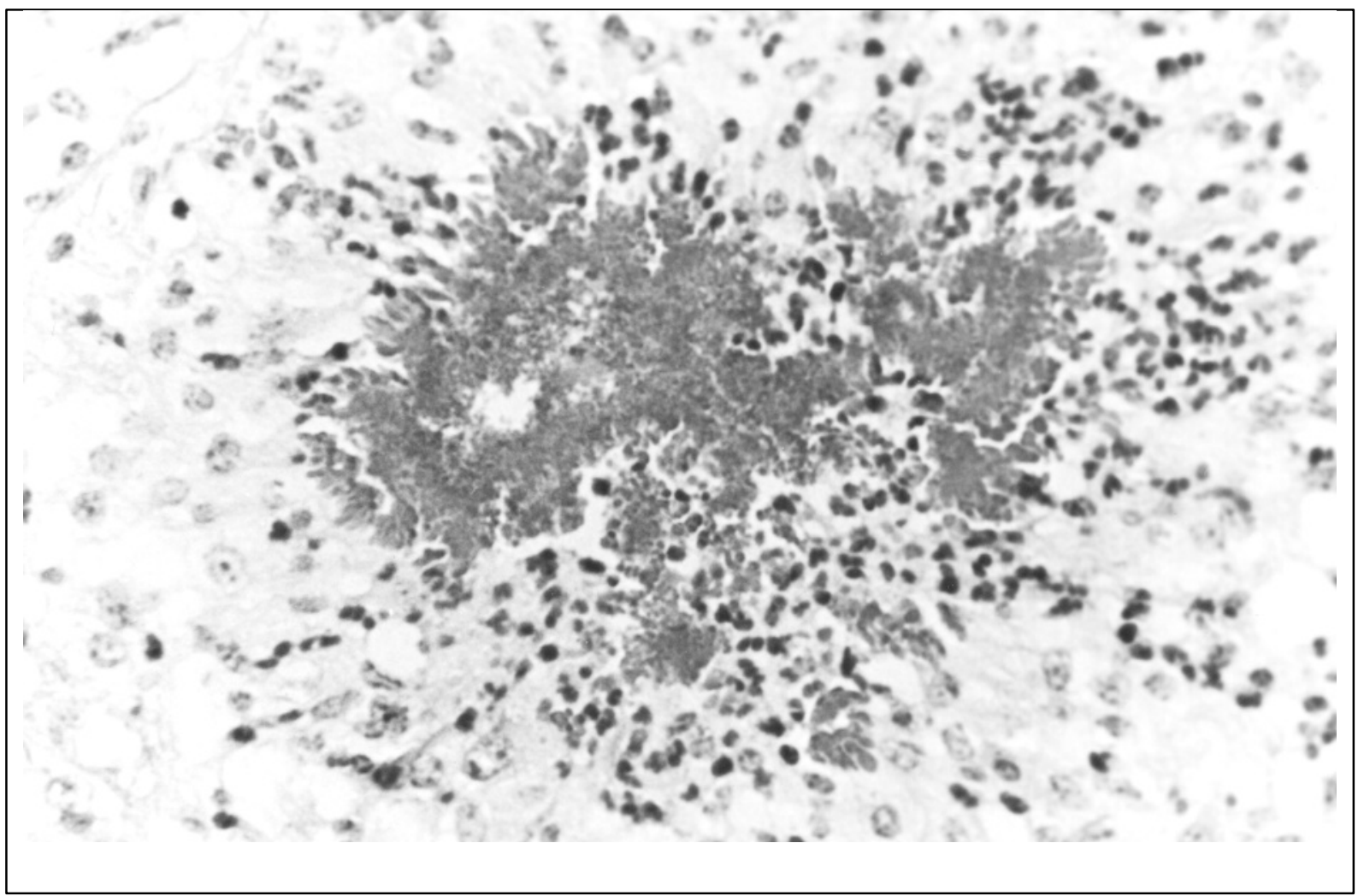

Figura 2 - Bovino. Piogranuloma. Observa-se piogranuloma, contendo uma roseta com colônias bacterianas no centro e corpúsculos de Splendore-Hoeppli. Circundando a roseta observam-se neutrófilos e, mais na periferia, células epitelióides e tecido fibroso infiltrado por linfócitos.

diferencia-se pelo envolvimento ósseo desta. A confirmação do diagnóstico é feita da mesma forma que na actinobacilose, sendo o agente isolado, neste caso, o Actinomyces bovis.

Observou-se que as características macroscópicas do granuloma eram semelhantes à tuberculose, podendo ele ser confundido com esta enfermidade, no entanto o teste de tuberculina foi negativo. Em um estudo realizado em Santa Maria (RS), em 467 linfonodos com lesões macroscópicas semelhantes à tuberculose, $10,23 \%$ evidenciaram outras causas através de estudo microscópico (WEISS \& SANTOS, 1992). Em outro estudo, realizado em abatedouros com Inspeção Federal no Rio Grande do Sul, foi detectado que $92,45 \%$ das lesões macroscopicamente semelhantes à tuberculose, tiveram diagnóstico positivo para esta enfermidade (ANDRADE $\boldsymbol{e t} \boldsymbol{a l}$. , 1991).

O tratamento da actinobacilose e actinomicose é baseado na aplicação de iodetos de sódio ou potássio ( $1 \mathrm{~g} / 12 \mathrm{~kg}$ de peso vivo) em solução a $10 \%$, por via endovenosa em uma única dose, associado à antibioticoterapia (sulfonodamidas, penicilina ou estreptomicina durante 3 a 4 dias). $\mathrm{Na}$ actinomicose, os tratamentos têm eficácia limitada, sendo o tratamento cirúrgico o mais recomendado (BLOOD \& RADOSTITS, 1991). Em animais de alto valor zootécnico, acredita-se que os granulomas actinomicóides podem ser tratados com maior eficiência através da excisão cirúrgica ou redução da lesão associado ao tratamento antimicrobiano prolongado, devido à presença da cápsula de tecido fibroso geralmente existente. Em casos que não seja possível o tratamento cirúrgico, a associação de iodetos à administração de antibióticos pode ser importante, da mesma forma que na actinobacilose, onde segundo BLOOD \& RADOSTITS (1991) os iodetos agem reduzindo a reação em que houver formação de tecido fibroso.

\section{CONCLUSÃO}

Conclui-se que $\boldsymbol{A}$. pyogenes poderia ter sido a causa de um granuloma actinomicóide com características clínicas e patológicas semelhantes à lechiguana, tuberculose e actinobacilose em bovinos. 
Tabela 1 - Caracterização bioquímica de Arcanobacterium pyogenes*.

\begin{tabular}{ll}
\hline Provas bioquímicas & Arcanobacterium pyogenes \\
\hline Catalase & - \\
Utilização de carboidratos & - \\
Lactose & - \\
Maltose & - \\
Manitol & - \\
Salicina & - \\
Sorbitol & - \\
Sacarose & - \\
Trealose & - \\
Xilose & - \\
Redução de nitrato & - \\
Indol & - \\
Hidrólise da gelatina & + \\
Voges-proskauer & - \\
Hidrólise da esculina & - \\
\hline
\end{tabular}

* BARROW \& FELTHAM (1993)

- Reação negativa

+ Reação positiva

\section{REFERÊNCIAS BIBLIOGRÁFICAS}

ANDRADE, G.B., RIET-CORREA, F., MIELKE, P.V., et al. Estudo histológico e isolamento de micobactérias de lesões similares à tuberculose em bovinos no Rio Grande do Sul. Pesq Vet Bras, v.11, n.3/4, p.81-86, 1991.

BLOOD, D.C., RADOSTITS, O.M., GAY, C.C. Clínica veterinária. 7.ed. Rio de Janeiro : Guanabara Koogan, 1991. 1263p.

BARROW, G.I., FELTHAM, R.K.A. Manual for identification of medical bacterial. $3^{\text {rd }}$.ed. Cambridge : University, 1993. $165 \mathrm{p}$.

GYLES, C.L. Nocardia; Actinomyces; Dermatophylus. In: GYLES, C.L., THOEN, C.O. Pathogenesis of bacterial infections in animals. $5^{\text {th }}$.ed. Iowa: University, 1986. Cap.12. p.87-94.

LUNA, G.L. Manual of histologic staining methods of the armed forces institute of pathology. 3.ed. New York: McGraw-Hill, 1968. 285p

McGAVIN, M.D. Músculos. In: CARLTON, W.W., McGAVIN, M.D. Patologia veterinária especial de Thomsom. 2.ed. Porto Alegre : ArtMed, 1998. Cap.9. p.417-446.
MÉNDEZ, M.D.C. Actinobacilose. In: RIET-CORREA, F. SCHILD, A.L., MÉNDEZ, M.D.C. Doenças de ruminantes e eqüinos. Pelotas : UFPel, 1998. Cap.3. p.140-145.

MONDADORI, A.J., RIET-CORREA, F., CARTER, G.R., $\boldsymbol{e}$ t al. Actinobacilose em bovinos no Rio Grande do Sul. Ciência Rural, v.24, n.3, p.571-577, 1994.

NARAYANAN, S., NAGARAJA, T. G., STAATS, J., $\boldsymbol{e} \boldsymbol{t} \boldsymbol{a l}$. Biochemical and biological characterizations and ribotyping of Actinomyces pyogenes and Actinomyces pyogenes-like organisms from liver abscesses in cattle. Vet Microbiol, v.61, n.4, p.289-303, 1998a.

NARAYANAN, S., NAGARAJA, T.G., WALLACE, N. Biochemical and ribotyping compararison of Actinomyces pyogenes and Actinomyces pyogenes-like organisms from liver abscesses, ruminal wall and ruminal contents of cattle. Am J Vet Res, v.59, n.3, p.271-276, 1998b.

OUCHTERLONY, O. Difusion in gel methods for immunology analysis. Progr Allergy, v.5, p.1-78, 1948.

PALMER, N.C. Bone and joints. In: JUBB, K.V.F., KENNEDY, P.C., PALMER, N.C. Pathology of domestic animals. 4.ed. Orlando : Academic, 1992. Cap.1. p.1-181.

PUGH, G.W. Jr., HUGLES, D., Mc DONALD, T.J. Bovine Infectious keratoconjunctivitis: serological aspects of Moraxella bovis infection. Can J Comp Med, v.37, p.70-78, 1971.

QUINN, P.J., CARTER, M.E., MARKEY, B.K., et al. Clinical veterinary microbiology. London: Wolf, 1994. 648p.

RIET-CORREA, F., LADEIRA, S.L., ANDRADE, G.B., et al. Lechiguana (Focal proliferative fibrogranulomatous panniculitis) in a cattle. Veterinary Research Communications. v.24, n.8, p.557-572, 2000.

SHANAN, M.S., DAVIS, C.L. The diagnosis of actinomycosis and actinobacilosis. Am J Vet Res, v.3, n.9, p.321-329, 1942.

WARD, J.L., REBHUN, W.C. Chronic frontal sinusitis in dary cattle 12 cases (1978-1989). J Am Vet Med Assoc, v.201, n.2, p.326-328, 1992.

WEISS, R.D.N., SANTOS, M.N. Determinação da etiologia de granulomas actinomicóides em bovinos no Rio Grande do Sul através da histoquímica. Pesq Vet Bras, v.12, n.3/4, p.71-76, 1992. 